\title{
Assessing the Levels of Knowledge About Common Causes and Treatments of Traumat- ic Dental Injuries Among General Dentists in the City of Bandar Abbas in 2018
}

\author{
M Zamanzadeh ${ }^{*}{ }_{1}$, A Rayani² $^{2}$, M Mirzaie $^{3}$, E Mahmoodnia $^{4}$
}

1- Assistant Professor, Department of Oral and Maxillofacial Pathology, Faculty of Dentistry, Mazandaran University of Medical Sciences, Sari, Iran

2- Assistant Professor, Department of Oral and Maxillofacial Pathology, Faculty of Dentistry, Qom University of

Medical Sciences, Qom, Iran.

3- Dentist, Tehran, Iran.

4- Student Research Committee, Babol university of Medical Science, Babol, Iran

ARTICLE INFO

Article History

Received: Nov 2019

Accepted: Dec 2019

ePublished: Feb 2020

Corresponding author:

M Zamanzadeh, Assistant

Professor, Department of

Oral and Maxillofacial

Pathology, Faculty of

Dentistry, Mazandaran

University of Medical

Sciences, Sari, Iran.

Email: zamanzadeh-

maryam@gmail.com

\begin{abstract}
Background and Aim: Traumatic dental injuries (TDIs) are among the urgent challenges in dental sciences. These types of trauma are a common dental health problem, which may affect hard tissues and tooth-supporting structures. Since dentists' knowledge and practice are vital for TDI treatments, this study aimed to assess the levels of knowledge of TDIs among general dentists working in Bandar Abbas, Iran.

Materials and Methods: This cross-sectional study was conducted on 97 general dentists working in the city of Bandar Abbas, Iran, using a three-part questionnaire comprising items about demographic characteristics, knowledge of TDI causes, and knowledge of TDI treatments. Descriptive and analytical statistical analyses of data were performed according to Mann-Whitney and Kruskal-Wallis tests using SPSS 20 software at the significance level of 0.05 .

Result: Ninety-seven general dentists, including 61 men and 36 women, participated in this study. The findings revealed that $60.9 \%$ and $46.4 \%$ of these dentists had high levels of knowledge about TDI causes and treatments, respectively. The mean score obtained by the general dentists was $11.86 \pm 2.87$, which was promising. A significant relationship was observed between university affiliation and levels of knowledge $(\mathrm{P}=0.002)$.

Conclusion: According to the results, knowledge about common causes and treatments of TDI was at a favorable level among the general dentists working in Bandar Abbas. There was a significant relationship between university affiliation and levels of knowledge; dentists who graduated from universities located in the city of Tehran, Iran, had higher levels of knowledge than others did.

Keywords: Knowledge, Trauma, Children, Dentoalveolar
\end{abstract}

J Res Dent maxillofac Sci 2020, 5(1):8-12

\section{Introduction:}

Management and treatment of traumatic dental injuries (TDIs) are among the main urgent challenges in dental sciences. The incidence of TDIs has been investigated in numerous settings and countries, reporting high rates. ${ }^{(1)}$ TDIs are known as a common dental health problem among children and adults, which can affect hard tissues and tooth-supporting structures. ${ }^{(2)}$
Falls, accidents, injuries sustained by cycling and other sports, car crashes, and some chronic diseases, such as epilepsy, are considered as the etiological factors of TDIs. (3) The prognosis of such dental traumas depends on the severity of injuries, the quality of timely primary care services, and follow-up. Following a reduction in the incidence and severity 
of tooth decay, there is an increasing interest in TDIs as the second common dental injuries that affect children and adolescents. ${ }^{(4)}$

TDIs are viewed as a public health problem due to their high rates of occurrence, high treatment costs, as well as long-term side effects of dental health services, demanding extensive lifetime care and treatment. Moreover, TDIs lead to pain, permanent cosmetic and functional problems, and psychological effects on children and parents as an unpredictable event, which needs dental care. ${ }^{(5)}$ Most injuries are associated with the incisors, such as enamel-dentin fractures involving the maxillary central incisors. ${ }^{(5)}$ Minor injuries to the teeth, including cracks and chipping as well as fractures of enamel or dentin, can be promptly treated. Such fractures must not be left untreated, and it is necessary to immediately cover the exposed dentin since it can be easily infected by the saliva, food, and bacteria, leading to pulpal necrosis. In addition, the missing tooth structure needs to be instantly replaced to prevent complications, such as tooth-induced labial protrusion, deviation or movement of adjacent teeth, and incisor overgrowth. ${ }^{(6)}$ Dentists must treat such patients using the most accurate methods or immediately refer them to specialists. ${ }^{(6)}$

Since good levels of knowledge and practice among dentists are of utmost importance in TDI treatment, this study aimed to evaluate the knowledge of TDIs among general dentists working in the city of Bandar Abbas, Iran.

\section{Materials and Methods}

In this cross-sectional study, all general dentists working in the city of Bandar Abbas, Iran, were recruited using the census method. In this study, a valid and reliable three-part questionnaire was used for data collection. ${ }^{(7)}$ The first part of this research instrument included items about demographic characteristics, and the second and the third parts contained items associated with dentists' knowledge of TDI causes and treatments, respectively.

The questionnaire included 18 questions; the correct answer to each question had a score of one. Three main items were related to the TDI causes (questions 3, 8, and 9) with minimum and maximum scores of zero and three, respectively. Mean scores lower than one indicated low levels of knowledge among general dentists, and scores of 1 to 2 and 2 to 3 represented good and excellent levels of knowledge, respectively. ${ }^{(7)}$ To address TDI treatments, fifteen items (questions $1,2,4-7$, and 10-18) were developed with 0 and 15 as the minimum and maximum scores, respectively. Accordingly, mean scores lower than five showed low levels of knowledge, scores between 5 and 10 denoted good levels of knowledge, and scores greater than 10 indicated excellent levels of knowledge.

In this study, the maximum score achievable in the field of "cause and treatment of dental trauma" was 18 . According to a general classification, mean scores lower than six, between six and 12, and between 13 and 18 suggested low, moderate/good, and excellent levels of knowledge, respectively. ${ }^{(7)}$

The data were imported into SPSS 20 software (IBM Corp., Armonk, NY, USA). Firstly, the data were analyzed using descriptive statistics, including mean, standard deviation (SD), and frequency/percentage, and then, analytical (inferential) statistics were utilized to reflect on the statistical correlations. The questionnaire is attached to the end of the article.

\section{Result:}

This study involved 97 general dentists, including 61 men (62.9\%) and 36 women (37.1\%). The mean age of the participants was $36.55 \pm 8.42$ years, ranging from 24 to 63 years. The average duration of work experience was $9.71 \pm 6.93$ years, ranging from at least 6 months to a maximum of 34 years. Table 1 shows the demographic characteristics of dentists. 
Table 1: Frequency/percentage of demographic characteristics among dentists

\begin{tabular}{cccc}
\hline Demographic variables & Frequency & Percentage \\
\hline Age group & Below 30 years old & 23 & 23.7 \\
\cline { 2 - 4 } & $30-40$ years old & 48 & 49.5 \\
\cline { 2 - 4 } & 40-50 years old & 15 & 15.5 \\
\cline { 2 - 4 } & Over 50 years old & 11 & 11.3 \\
\hline Dentistry & Less than 10 years & 49 & 50.5 \\
\cline { 2 - 4 } $\begin{array}{c}\text { work } \\
\text { experience }\end{array}$ & Between 10 and 20 years & 39 & 40.2 \\
\cline { 2 - 4 } University & More than 20 years & 9 & 9.3 \\
\cline { 2 - 4 } affiliation & Tehran & 27 & 27.8 \\
\cline { 2 - 4 } & Other cities & 61 & 62.9 \\
\hline History of \\
\cline { 2 - 4 } participation \\
in retraining & Abroad & 9 & 9.3 \\
courses & Yes & 46 & 47.4 \\
\hline Number of & No & 51 & 52.6 \\
\cline { 2 - 4 } exposures to & & 13 & 13.4 \\
\cline { 2 - 4 } $\begin{array}{c}\text { TDI cases } \\
\text { per year }\end{array}$ & Often & 59 & 60.8 \\
\cline { 2 - 4 } & Rarely & 20 & 20.6 \\
\hline Knowledge & Sometimes & 63 & 64.9 \\
\cline { 2 - 4 } $\begin{array}{c}\text { self- } \\
\text { assessment }\end{array}$ & Never & 15.5 \\
\cline { 2 - 4 } & Sufficient & 19 & 19.6 \\
\hline
\end{tabular}

\section{TDI=Traumatic Dental Injuries}

Overall, $47.4 \%$ of the dentists had a history of participation in retraining courses. The majority of the dentists (60.8\%) reported that they had rarely encountered TDIs, and $64.9 \%$ of them felt that they had sufficient knowledge in this field. The mean score of levels of knowledge of common TDI causes among the dentists was $1.73 \pm 1.08$, and $60.9 \%$ of them were at excellent levels. The mean score associated with the levels of knowledge about common TDI treatments among these dentists was $10.1 \pm 2.6$, varying between 4 and 15 . Overall, $49.5 \%$ of the dentists had good levels of knowledge in this respect. The mean score of the levels of knowledge about common TDI causes and treatments was $11.86 \pm 2.87$, and $50.5 \%$ of the dentists had good levels of knowledge in this respect (Table 2).
Table 2: Frequency/percentage of levels of knowledge among dentists about common causes and treatments of traumatic dental injuries (TDI) with a $95 \%$ confidence interval (CI)

\begin{tabular}{cccc}
\hline $\begin{array}{c}\text { Dentists' } \\
\text { knowledge }\end{array}$ & Levels & Frequency & Percentage \\
\hline TDI causes & Low & 17 & 17.5 \\
\cline { 2 - 4 } & Good & 21 & 21.6 \\
\cline { 2 - 4 } & Excellent & 59 & 60.9 \\
\hline TDI & Low & 4 & 4.1 \\
\cline { 2 - 4 } treatments & Good & 48 & 49.5 \\
\cline { 2 - 4 } & Excellent & 45 & 46.4 \\
\hline TDI causes & Low & 5 & 5.2 \\
\cline { 2 - 4 } and & Good & 49 & 50.5 \\
\cline { 2 - 4 } treatments & Excellent & 43 & 44.3 \\
\hline
\end{tabular}

Table 3 represents the correlation between the dentists' demographic characteristics and their levels of knowledge. Accordingly, there was no statistically significant relationship between gender, age, work experience, graduation year, history of retraining, and knowledge self-assessment, and only a significant relationship was observed between levels of knowledge and university affiliation. Dentists who graduated from dental schools located in the city of Tehran, Iran, showed the highest levels of knowledge, followed by those who graduated from other cities and dental students; abroad graduates had the lowest levels of knowledge of TDI causes and treatments $(\mathrm{P}=0.002)$. 
Table 3:Relationship between dentists' demographic characteristics and mean scores of knowledge level

\begin{tabular}{|c|c|c|c|}
\hline \multicolumn{2}{|c|}{ Demographic variables } & \multirow{2}{*}{$\begin{array}{l}\text { Mean } \pm \text { SD } \\
12.05 \pm 2.9\end{array}$} & \multirow{3}{*}{$\begin{array}{l}\text { Test results } \\
\mathrm{P}=0.361\end{array}$} \\
\hline \multirow{2}{*}{ Gender } & Male & & \\
\hline & Female & $11.53 \pm 2.8$ & \\
\hline \multirow{2}{*}{ Age } & $\begin{array}{l}\text { Below } 36.5 \\
\text { years }\end{array}$ & $11.65 \pm 93.2$ & $\mathrm{P}=0.347$ \\
\hline & $\begin{array}{l}\text { Over } 36.5 \\
\text { years }\end{array}$ & $12.23 \pm 2.76$ & \\
\hline \multirow{2}{*}{$\begin{array}{l}\text { Dentistry work } \\
\text { experience }\end{array}$} & $\begin{array}{l}\text { Below } 9.7 \\
\text { years }\end{array}$ & $11.33 \pm 3.11$ & $\mathrm{P}=0.074$ \\
\hline & $\begin{array}{l}\text { Over } 9.7 \\
\text { years }\end{array}$ & $12.4 \pm 2.52$ & \\
\hline \multirow{3}{*}{ Graduation year } & Before & $12.51 \pm 2.69$ & $\mathrm{P}=0.078$ \\
\hline & 2007 & & \\
\hline & After 2007 & $11.48 \pm 2.92$ & \\
\hline \multirow{3}{*}{$\begin{array}{l}\text { University } \\
\text { affiliation }\end{array}$} & Tehran & $13.07 \pm 2.53$ & $\mathrm{P}=0.002^{*}$ \\
\hline & $\begin{array}{l}\text { Other } \\
\text { cities }\end{array}$ & $11.74 \pm 2.77$ & \\
\hline & Abroad & $9 \pm 2.35$ & \\
\hline \multirow{2}{*}{$\begin{array}{l}\text { History of } \\
\text { retraining }\end{array}$} & Yes & $12.22 \pm 2.62$ & $\mathrm{P}=0.254$ \\
\hline & No & $11.53 \pm 3.06$ & \\
\hline \multirow{4}{*}{$\begin{array}{c}\text { Number of } \\
\text { exposures to TDI } \\
\text { cases per } \\
\text { year }\end{array}$} & Often & $11.46 \pm 2.73$ & $\mathrm{P}=0.595$ \\
\hline & Rarely & $11.75 \pm 2.84$ & \\
\hline & Sometimes & $12.15 \pm 3.12$ & \\
\hline & Never & $13 \pm 2.92$ & \\
\hline \multirow{3}{*}{$\begin{array}{c}\text { Knowledge self- } \\
\text { assessment }\end{array}$} & Sufficient & $11.84 \pm 3.69$ & $\mathrm{P}=0.662$ \\
\hline & High & $11.75 \pm 69.2$ & \\
\hline & Insufficient & $12.33 \pm 2.58$ & \\
\hline
\end{tabular}

$\overline{T D I=\text { Traumatic Dental Injuries, } S D=\text { Standard Deviation }}$

\section{Discussion:}

The incidence of TDIs in children aged up to 15 years has been reported to be 7\%-50\%.(8) Epidemiological studies have further revealed that the prevalence of TDIs depends on statistical populations and their nationality, age, and gender, as well as the status of healthcare services, and TDI classifications; therefore, their results cannot be easily compared..$^{(9)}$

According to a systematic study by Glendor (2008), one-third of preschool children suffer from TDIs, which affect their deciduous teeth. ${ }^{(10)}$ Moreover, it has been reported that over a quarter of school children and approximately one-third of adults suffer from TDIs that affect their permanent teeth; however, there are differences between various countries. ${ }^{(10)}$ In the present study, about half of the general dentists working in the city of Bandar Abbas had good levels of knowledge of TDI causes and treatments. In a study by Nilchian et al (2014) in the city of Isfahan, Iran, dentists' general knowledge was also reported to be at good levels. ${ }^{(7)}$ In a survey by Tafaroji et al (2017) in the city of Semnan, Iran, $75.4 \%$ of the dentists answered all the questions correctly. ${ }^{(1)}$

In a study conducted in the city of Ahwaz, Iran, Basir et al (2016) found that $51 \%$ of a total number of 100 dentists had good levels of knowledge; the overall knowledge of the general dentists regarding TDIs was reported to be at a good level. ${ }^{(12)}$ Seraj et al (2008) also revealed that dentists' knowledge of TDIs affecting children in the city of Tehran, Iran, was relatively good. ${ }^{(13)}$ In their study, the levels of knowledge of the dentists positively correlated with their graduation year and inversely correlated with their age. ${ }^{(13)}$ This is in contrast to the findings of the present study as well as those reported by Tafaroji et al (2017) ${ }^{(11)}$ They found no significant relationship between the dentists' graduation year and age and their levels of knowledge. ${ }^{(11)}$

Furthermore, there was no significant difference between levels of knowledge and gender in the present study. Seraj et al found no significant difference between gender and levels of knowledge, which is in line with the findings of the present study. ${ }^{(13)}$

In a study by Krastl et al (2009), 63\% of German dentists had sufficient knowledge of TDI treatments. ${ }^{(14)}$ de Vasconcellos et al (2009), in Tanzania, similarly reported that levels of knowledge about TDI causes and prevention in a group of dentists were sufficient although they had insufficient knowledge about treatments. ${ }^{(15)}$ The reason for differences with the results of the present study could be variances in measurement instruments as well as discrepancies in levels of dental education.

In an investigation by Abu-Dawoud et al (2007), levels of knowledge among physicians and dentists about avulsed teeth were further compared; it was reported that the dentists had good levels of knowledge, which were higher than that of the physicians (16). In a study by Hu et al (2013) in Brazil, levels of knowledge of general dentists and endodontists about emergency management of dentoalveolar traumas were compared; the results indicated that the levels of knowledge among endodontists were higher than that of general dentists. ${ }^{(17)}$ They concluded that general dentists should attend training programs to improve their knowledge about TDIs. ${ }^{(17)}$

The results of the present study demonstrated that the general dentists' knowledge of TDIs was good; nonetheless, continuous training courses, as well as workshops and conferences, would help in maintaining the results and even improving the dentists' practices. 


\section{Conclusion:}

Of the total number of 97 dentists in this study, $60.9 \%$ and $46.4 \%$ showed high levels of knowledge of TDI causes and treatments, respectively.

The level of knowledge about TDI causes and treatments was also good among most of the dentists. There was a statistically significant correlation between university affiliation and levels of knowledge such that dentists who graduated from universities located in the city of Tehran, Iran, had higher levels of knowledge.

\section{References:}

1.Andreasen JO, Andreasen FM. Textbook and Color Atlas of Traumatic Injuries to the Teeth. Copenhagen. Munksgaard, 1994:151-77.

2.Re D, Augusti D, Paglia G, Augusti G, Cotti E. Treatment of traumatic dental injuries: evaluation of knowledge among Italian dentists. Eur J Paediatr Dent. 2014 Mar;15(1):23-8.

3.Lee JY, Divaris K. Hidden consequences of dental trauma: the social and psychological effects. Pediatr Dent. 2009 Mar-Apr;31(2):96-101.

4.Ferreira J, Fernandes de Andrade EM, Katz CR, Rosenblatt A. Prevalence of dental trauma in deciduous teeth of Brazilian children. Dent Traumatol. 2009 Apr;25(2):219-23.

5.Siqueira MB, Gomes MC, Oliveira AC, Martins CC, Granville-Garcia AF, Paiva SM. Predisposing factors for traumatic dental injury in primary teeth and seeking of post-trauma care. Braz Dent J. 2013 NovDec;24(6):647-54.

6.Alani A, Austin R, Djemal S. Contemporary management of tooth replacement in the traumatized dentition. Dent Traumatol. 2012 Jun;28(3):183-92.

7.Nilchian F, Akhlaghi N, Ganji S. Evaluation of knowledge of Isfahan dentists about etiology, prevention and common treatment modalities of dental trauma. J Isfahan Dent Sch. 2014 Dec;10(5):370-81.

8.Kahabuka F, Plasschaert A, van't Hof M. Prevalence of teeth with untreated dental trauma among nursery and primary school pupils in Dar es Salaam, Tanzania. Dent Traumatol. 2001 Jun;17(3):109-13.

9.Kawachi I, Subramanian SV. Measuring and modeling the social and geographic context of trauma: a multilevel modeling approach. J Trauma Stress. 2006 Apr;19(2):195-203.

10. Glendor U. Epidemiology of traumatic dental injuries--a 12-year review of the literature. Dent Traumatol. 2008 Dec;24(6):603-11.

11.Tafaroji R, Kameli S, Nourelahi M, Ghorbani R, Raz H, Naghipur A. Evaluation of the dentists' knowledge on dental trauma. Koomesh. 2017;19(4):760-5.

12. Basir L, Shayesteh M, Atiyeh Heydari M, Imani
Z, Momedi Kartalaee M. General dental practitioners' knowledge and attitude regarding management of dental trauma in children of Ahvaz city. Jundishapur Sci Med J. 2016;15(3):371-82.

13. Seraj B, Shahrabi M, Bijani M, Haeri Mehrizi AA. General dental practitioners and management of traumatic dental injuries in children. J Islam Dent Assoc Iran. 2008;19(4):18-22.

14. Krastl G, Filippi A, Weiger R. German general dentists' knowledge of dental trauma. Dent Traumatol. 2009 Feb;25(1):88-91.

15. de Vasconcellos LG, Brentel AS, Vanderlei AD, de Vasconcellos LM, Valera MC, de Araújo MA. Knowledge of general dentists in the current guidelines for emergency treatment of avulsed teeth and dental trauma prevention. Dent Traumatol. 2009 Dec;25(6):57883.

16. Abu-Dawoud M, Al-Enezi B, Andersson L. Knowledge of emergency management of avulsed teeth among young physicians and dentists. Dent Traumatol. 2008 Dec;23(6):348-55.

17. Hu LW, Prisco CR, Bombana AC. Knowledge of Brazilian general dentists and endodontists about the emergency management of dento-alveolar trauma. Dent Traumatol. 2006 Jun;22(3):113-7.

18. Vatanpour M, Azimi CH, Masoumi Z .Study of the knowledge of elementary school health teachers of Tehran city on how to control students' teeth injuries at school in 2014. J Res Dentomaxillofac Sci. 2017; 2 (1):36-41.

Please cite this paper as:

M Zamanzadeh, A Rayani, M Mirzaie, E Mahmoodnia. Assessing the Levels of Knowledge About Common Causes and Treatments of Traumatic Dental Injuries Among General Dentists in the City of Bandar Abbas in 2018. J Res Dentomaxillofac Sci. 2020; 5(1) :8-12 